\title{
RESERVA DE VAGAS EM UNIVERSIDADES PÚBLICAS ESTADUAIS: IMPLICAÇÕES PARA A DOCÊNCIA UNIVERSITÁRIA
}

\author{
RESERVA DE PLAZAS EN LAS UNIVERSIDADES PÚBLICAS ESTATALES: \\ IMPLICACIONES PARA LA ENSEÑANZA UNIVERSITARIA
}

\author{
RESERVATION OF VACANCIES AT STATE PUBLIC UNIVERSITIES: \\ IMPLICATIONS FOR UNIVERSITY TEACHING
}

\author{
Ana Cristina Silva SOARES ${ }^{1}$ \\ Valéria de OLIVEIRA ${ }^{2}$
}

RESUMO: Objetivando analisar a articulação entre a reserva de vagas de duas instituições públicas de ensino superior e a docência universitária para práticas pedagógicas que visem combater a desigualdade racial, social e cultural, esse artigo tem como premissa a equidade de oportunidades. Para tanto, busca articular as ideias teóricas de Mantoan (2013), Rodrigues e Garzón (2012), Pimenta e Anastasiou (2005), Booth e Ainscow (2002), Sawaia (2014) na constituição dos saberes dos professores para o ensino com inclusão; bem como na emergente necessidade de superação de paradigmas de reprodução, tanto das práticas docentes quanto dos processos de formação desses professores. As questões de pesquisa giram em torno de: Como as diferentes concepções de inclusão dialogam no processo de formação de professores e de ensino-aprendizagem destes professores em relação ao combate da desigualdade racial, social e cultural? Que evidências o campo da docência universitária de duas instituições de ensino superior diz sobre as experiências das reservas de vagas, que caminham para redução das desigualdades entre estudantes beneficiados por políticas de ações afirmativas? Tem como método a análise de conteúdo de fontes documentais que normatizam as cotas na Universidade, sendo lócus da pesquisa: Universidade Estadual Vale do Acaraú (UVA), Sobral, CE e Universidade do Estado do Rio de Janeiro (UERJ), Rio de Janeiro, RJ. Evidencia que a institucionalização da política de ação afirmativa (cotas sociais) na UVA e UERJ tem ampliado o acesso de graduandos oriundos de escolas públicas, inclusive, em cursos de perfil historicamente elitizado.

PALAVRAS-CHAVE: Reserva de vagas. Prática docente. Ensino superior. Desigualdade social. Inclusão acadêmica.

RESUMEN: Con el objetivo de analizar la articulación entre la reserva de plazas vacantes de dos instituciones públicas de educación superior y la docencia universitaria para prácticas pedagógicas que intentan combatir la desigualdad racial, social y cultural, este artículo presenta como premisa la equidad de oportunidades. Así pues, busca articular las

1 Universidade Estadual Vale do Acaraú (UVA), Sobral - CE - Brasil. Docente Adjunto I. Curso Pedagogia. Centro de Filosofia, Letras e Educação - CENFLE. ORCID: https://orcid.org/0000-0002-0211-965X. E-mail: acsilvasoares@gmail.com

${ }^{2}$ Universidade do Estado do Rio de Janeiro (UERJ), Rio de Janeiro - RJ - Brasil. Docente Assistente. Faculdade de Educação e Instituto Fernando Rodrigues da Silveira - CAP-UERJ. ORCID: https://orcid.org/0000-00017230-8379. E-mail: valeriagpdoc@gmail.com 
ideas teóricas de Mantoan (2013), Rodrigues y Garzón (2012), Pimenta y Anastasiou (2005), Booth y Ainscow (2002), y Sawaia (2014) en la constitución de los conocimientos de los docentes para la enseñanza con inclusión; al igual que la necesidad emergente de superar los paradigmas de la reproducción, tan de las prácticas de la docencia como de los procesos de formación de estos docentes. Las preguntas de la investigación giran alrededor de: ¿Cómo dialogan las diferentes concepciones de la discapacidad en el proceso de formación y enseñanza-aprendizaje de estos profesores en relación con la lucha contra la desigualdad racial, social y cultural? ¿Qué evidencias dice el campo de la docencia universitaria de dos instituciones de educación superior sobre las experiencias de las reservas de plazas vacantes que apuntan a reducir las desigualdades entre los estudiantes beneficiados por las politicas de acción afirmativa? El método utilizado analiza el contenido de las fuentes documentales que regulan las cuotas en la Universidad, siendo sitios de la investigación: Universidad Estatal del Vale do Acara (UVA), Sobral, Ceará y Universidad Estatal de Río de Janeiro (UERJ), Río de Janeiro, RJ. Como resultado muestra que la institucionalización de la política de acción afirmativa (cuotas sociales) en UVA y UERJ ha aumentado el acceso de los estudiantes de pregrado de las escuelas públicas, incluso en cursos con un perfil históricamente elitizado.

PALAVRAS-CLAVE: Reserva de plazas. Práctica docente. Educación superior. Desigualdad social. Inclusión académica.

ABSTRACT: This article is premised on equity of opportunity, because it aims to analyze the articulation between the reserve of vacancies of two public universities and university teaching for pedagogical practices that have the purpose of combating race, social and cultural inequality. To this end, it seeks to articulate the theoretical ideas Rodrigues and Garzón (2012), Mantoan (2013), Pimenta and Anastasiou (2005), Booth and Ainscow (2002), and Sawaia (2014) in the constitution of teachers' knowledge for teaching with inclusion; as well as the emerging need for overcoming reproduction paradigms, both of the teaching practices and the processes of formation of these teachers. It raises questions such as: How do different conceptions of disability dialogue in the process of teacher in relation to the fight against race, social and cultural inequality? What evidence does the field of university teaching at two public universities say about experiences of vacancy reserves, which lead to the reduction of inequalities among students benefited by affirmative action policies? It has as method of analysis of content of sources that standardizes as quoted in the University, being searched: Vale do Acaraú State University UVA), Sobral, Ceará and State University of Rio de Janeiro (UERJ), Rio de Janeiro, RJ. Evidence that institutionalizes the policy of affirmative (social quotas) action at UVA and UERJ has expanded or access to university students from public schools, including courses of historically elitist profile.

KEYWORDS: Reservation of vacancies. Teaching practice. University education. Social inequality. Academic inclusion.

\section{Introdução}

As ações afirmativas são políticas públicas que buscam diminuir a lacuna existente entre classes, grupos e indivíduos, promovendo a inclusão de todos esses historicamente marginalizados. Logo, visto que a educação é um dos direitos sociais dos cidadãos brasileiros, 
cabe-nos refletir sobre a reserva de vagas nas universidades públicas, uma dessas políticas que visam retificar a desigualdade estabelecida historicamente existente desde a formação da nação brasileira. Nesse contexto, é a partir da garantia de igualdade de condições de acesso a espaços, práticas e serviços educacionais que nesse artigo são evidenciadas as atuações de duas universidades públicas estaduais do País.

Embora as instituições de ensino superior, Universidade Estadual Vale do Acaraú (UVA) e Universidade do Estado do Rio de Janeiro (UERJ), tenham construído suas bases culturais de práticas de inclusão em momentos históricos distintos, com mais de uma década de diferença, ambas vêm se dedicando a práticas acadêmicas inovadoras, as quais contribuem para a formação inicial de seus graduandos, ao mesmo tempo em que permitem que seu corpo docente tenha a oportunidade de se formar em serviço.

Como ponto de partida, temos a perspectiva da Universidade do Estado do Rio de Janeiro (UERJ), pioneira em investir num sistema de reserva de vagas para diferentes categorias, inclusive para estudantes com deficiência, e a Universidade Estadual Vale do Acaraú (UVA), cuja prática de inclusão passou a ser implementada há pouco tempo.

A UERJ vem investindo no processo de reserva de vagas há 19 anos. Em 2000, a Assembleia Legislativa do Estado do Rio de Janeiro (ALERJ) aprovou a Lei $\mathrm{n}^{0} 3.524$, que determinou a reserva de $50 \%$ das vagas da UERJ. Desde então, cinco novas leis foram promulgadas estabelecendo mudanças na legislação vigente, sendo a última alteração realizada em 2018, a qual prorroga as reservas por mais dez anos. No Estado do Ceará, a Lei $\mathrm{n}^{\mathrm{o}} 16.197 / 2017$ instituiu por menos de uma década o sistema de cotas para ingresso às universidades e demais instituições de ensino superior.

A educação superior é um espaço marcado pela desigualdade de acesso e permanência de populações historicamente excluídas. Contudo, com a política de reserva de vagas, o papel da docência universitária vê-se em uma emergência de construir novos saberes que se considerem elementos de práticas pedagógicas inclusivas. Portanto, as questões principais desta pesquisa giram em torno de: Como as diferentes concepções de inclusão dialogam no processo de formação de professores e de ensino-aprendizagem destes professores em relação ao combate da desigualdade racial, social e cultural? Que evidências o campo da docência universitária de duas instituições de ensino superior diz sobre as experiências das reservas de vagas que caminham para redução das desigualdades entre estudantes beneficiados por políticas de ações afirmativas?

Desse modo, partindo da premissa da equidade de oportunidades, este artigo tem como objetivo principal analisar a articulação entre a reserva de vagas de duas instituições públicas 
de ensino superior e a docência universitária para práticas pedagógicas que visem combater a desigualdade racial, social e cultural, no nosso caso em específico, a estudantes com deficiência.

\section{Universidade Pública: transmissão cultural e ações inclusivas}

Compreende-se o papel da universidade pública como um lugar de transmissão da cultura, ensino das profissões, investigação científica, educação ética e moral, compromisso social com o conhecimento produzido e a formação de quadros (CHAUI, 2001). Por muito tempo, falar de universidade era falar de um lugar de acesso privilegiado das classes mais favorecidas, de pessoas brancas e consideradas "normais"; assim, tal lugar não era para pobres, negros e para pessoas com deficiência, de modo que, na atualidade, viu-se a necessidade de criar reserva de vagas para essas pessoas, que por longos anos foram impedidas de acessar esse espaço. Ainda com essas políticas, em alguns locais existem barreiras para o desenvolvimento de projetos que incentivem o uso de reservas de vagas para estudantes com deficiência.

Diferente da inclusão no ensino básico, a inclusão no ensino superior acontece por processo seletivo. Educação básica e educação superior diferenciam-se também quanto às finalidades, mas complementam-se, pois enquanto a primeira tem a finalidade de desenvolver uma formação escolar, oferecendo meios para que os alunos possam progredir no trabalho e em estudos posteriores, a segunda tem por fim estimular a criação cultural, o espírito científico e o pensamento reflexivo, formando-os em diferentes áreas do conhecimento.

A partir de 1990, a expansão do ensino superior tornou-se uma questão premente nas ações e nos discursos políticos para democratização do ensino, que envolve um fator de crescimento e de desenvolvimento social. Os estudos, conferências internacionais ${ }^{3}$ e ações governamentais sobre inclusão de estudantes com deficiência ligadas à educação básica avançaram e, como consequência, esses estudantes alcançam cada vez mais os níveis mais elevados de escolarização.

Parra e Infante (2006) discutem a questão da igualdade e equidade no ensino superior como valores de ajustamento social, desenvolvimento em educação e formação do indivíduo. Esses autores ressaltam que os estudantes com deficiência no ensino superior são colocados em uma circunstância particular, isto é, suas necessidades educacionais específicas são

3 Conferência Mundial de Educação para Todos, Jomtien (1990), Conferência Mundial de Necessidades Educativas Especiais: Acesso e Qualidade, Salamanca (1994) e Conferência Mundial sobre Ensino Superior, Paris (2009). 
consideradas e atendidas. Para eles, a inclusão exige recursos (financeiros, humanos, técnicos), preparação de pessoas, mudança organizacional da instituição para compensar o aspecto acadêmico, padronizando o desenvolvimento de um treinamento para pessoas que atendam os alunos com deficiência no ensino superior; entretanto, beneficia as mais variadas pessoas com deficiências.

No aspecto referente aos fatores pragmáticos à inclusão, os trabalhos de Karagiannis, Stainback e Stainback (1999) abordam os benefícios da educação inclusiva. Há alguns aspectos envolvendo alunos, professores e a comunidade em geral que são enfatizados, bem como as atitudes positivas e a capacitação de professores. Destacam que nas salas de aula todas as crianças ganham por terem a oportunidade de aprenderem umas com as outras, desenvolvem-se para cuidar umas das outras e conquistam as atitudes, as habilidades e os valores necessários para exercerem a cidadania.

Consideramos que o sucesso da inclusão envolve um conjunto de elementos: alunos, professores, comunidade, apoio, flexibilidade, recursos, atualização, colaboração, e planejamento. Além desses aspectos que são importantes, a educação inclusiva necessita da criação de um trabalho de Coordenação de Necessidades Especiais, com um local para auxiliar os profissionais da instituição de ensino. Para Mittler (2003), o papel do Coordenador de Necessidades Especiais, tanto na escola quanto na universidade, precisa ser visto como um facilitador ou um gerente, como alguém com a tarefa de apoiar os colegas e o sistema de ensino, a fim de responderem às necessidades de todos os alunos, embora nesse local haja várias percepções acerca da inclusão.

As concepções de inclusão apresentadas são complementares, ligam-se a diversos campos, como: política, filosofia, educação e cultura. Essas interligações, geralmente, dão conta de responder às questões relacionadas às concepções de inclusão de estudantes com deficiência em sistema regular de ensino, propõem mudanças de concepção de educação, filosofia, pedagogia, adaptação de espaço físico, correspondendo à diversidade dos estudantes, o que valoriza as condições e as diferenças individuais, que devem ser vistas não só como um problema a ser resolvido, mas como uma oportunidade para enriquecer o aprendizado (AINSCOW, 2009).

Cabe aqui inserirmos algumas ideias de inclusão, a partir do livro "As artimanhas da exclusão: análise psicossocial e ética da desigualdade social", de Bader Sawaia, que apresenta reflexões sobre a dialética da exclusão/inclusão. Para autora, “[...] esta concepção inverte a ideia de inclusão social, desatrela-se da noção de adaptação e normatização, gerando a culpabilização individual." Com isso, introduz a ética e a subjetividade da análise sociológica 
da desigualdade que amplia as interpretações legalistas, minimalistas da inclusão baseada em justiça social e restrita à crise do Estado. Para autora, a "sociedade exclui para incluir" (SAWAIA, 2014, p. 8).

Outra ideia surge no sentido do 'diferenciar para incluir', sendo possível quando o estudante ou beneficiário de uma ação afirmativa qualquer estiver no gozo do direito de escolha ou não dessa diferenciação. Um exemplo desse direito é o estudante que pode optar pelo lugar que ocupará em uma sala de aula quando usa cadeira de rodas (MANTOAN, 2013, p. 30).

No Brasil, em 2008, o Governo Federal assume um papel relevante com a divulgação da proposta da Política Nacional de Educação Especial na perspectiva da Educação Inclusiva, defendendo a inclusão como uma ação política, social, pedagógica e cultural. Neste campo, surge a demanda pela inclusão de estudantes com deficiência em sistemas de ensino. Tal proposta determina a garantia do direito de todos os estudantes de compartilharem do mesmo sistema de ensino, sem nenhuma forma de discriminação.

As determinações desta Política orientam os sistemas de ensino no sentido de se garantir o acesso à escola comum, com participação, aprendizagem e continuidade nos níveis mais elevados de escolaridade. Trata da transversalidade da modalidade da educação especial desde a educação infantil até à educação superior. A política possui ações oferecidas pela Educação Especial, tais como: oferta e instituição do Atendimento Educacional Especializado (AEE); formação de professores e demais profissionais da educação para o AEE; estímulo à participação da família e da comunidade na escola; ações de acessibilidade arquitetônica; acesso à escola com apoio de programa de transporte, acessibilidade de mobiliários, comunicações e informação; além da articulação intersetorial para a implementação de políticas públicas. Assim, os sistemas de ensino devem criar condições de acesso aos espaços, aos recursos pedagógicos e à comunicação que favoreçam a promoção da aprendizagem e a valorização das diferenças, de forma a atender as necessidades educacionais de todos os estudantes (BRASIL, 2008).

Segundo Rodriguez e Garzón (2012, p. 229), a universidade, por natureza, é o lugar “de todos os domínios relevantes do discurso que refletem, em seu conjunto, a soma total do conhecimento humano, um verdadeiro universo de atividades intelectuais", que na atualidade corre o risco de perder o sine qua non de sua existência: conservar, fazer progredir e disseminar o conhecimento independente. Segundo eles, a democracia se constrói, portanto, a partir de baixo, não como o desenvolvimento progressivo e ordenado de uma ideia de cidadania que já está esclarecida de uma vez por todas, mas como a re-criação constante e 
conflituosa do próprio mundo da vida.

A tradição de formação do professor de ensino superior, por sua vez, está assentada na pesquisa, conforme os padrões de qualidades determinados pela pós-graduação stricto sensu. Pela análise da realidade, verificamos que os programas de doutorado e mestrado são configurados numa forma que privilegia a especialização numa ênfase ao conhecimento e numa preparação para a pesquisa.

A universidade é, então, uma das instituições que oferece a educação superior e ela possui como uma de suas orientações a mencionada indissociabilidade entre o ensino, a pesquisa e a extensão. A Lei de Diretrizes e Bases da Educação, no 9394, de 1996, dispõe em seu artigo 52 que "As universidades são instituições pluridisciplinares de formação dos quadros profissionais de nível superior, de pesquisa, de extensão e de domínio e cultivo do saber humano".

De acordo com o Instituto Nacional de Estudos e Pesquisas Educacionais Anísio Teixeira (2016), no que se refere ao Censo do Ensino Superior, observa-se o registro de 12.290 ingressantes de graduação declarados como deficientes, com transtorno global do desenvolvimento ou altas habilidades/superdotação, equivalente a $0,4 \%$ do total de ingressantes, lembrando que um mesmo ingressante pode apresentar mais de um tipo de declaração. Entre as declarações mais comuns, 35,8\% aparecem como deficientes físicos, $29,8 \%$ registram baixa visão e 13,2\%, deficiência auditiva. Esses resultados propiciam que o tema seja considerado como foco para o desenvolvimento de políticas de acesso e permanência para estes ingressantes.

\section{Docência universitária e prática pedagógica: refletindo sobre inclusão e diferença}

$\mathrm{Na}$ perspectiva da construção efetiva de uma educação inclusiva há dois tipos de formação profissional: a primeira refere-se aos professores do ensino regular com vistas a um mínimo de formação; e a segunda trata dos professores especializados, segundo o autor, nas diferentes "necessidades educativas especiais", seja para o atendimento direto a essa população, seja para o apoio ao trabalho realizado por professores de salas de aula comum que integrem esses alunos (BUENO, 1999).

Libâneo (2000) afirma que a educação envolve uma atividade prática que se realiza de maneira artesanal, improvisada, ou que segue leis e princípios decorrentes da investigação científica. Também enfatiza que atualmente não é mais tempo de opor conhecimento científico e conhecimento prático. Explica que o saber da experiência se soma ao saber das 
leis explicativas e "universais", de modo que consideramos que a presença de estudantes com deficiência em espaços educativos pode favorecer para que o trabalho pedagógico organize processos de ensino-aprendizagem considerando as necessidades educativas desses estudantes, a heterogeneidade, linguagem, comunicação, uso de recursos didáticos acessíveis, desenho universal, etc.

Booth e Ainscow (2002) propõem uma associação entre três dimensões, as quais estão inter-relacionadas. Essas dimensões são: cultural, política e prática. A dimensão cultural refere-se ao estabelecimento de uma cultura baseada em princípios e valores inclusivos, ou seja, uma cultura inclusiva. O estabelecimento de uma cultura inclusiva no ambiente escolar propõe o desenvolvimento de valores que mobilizem as pessoas a pensar, a compartilhar e a se respeitar. Propõe o estímulo à criação de uma comunidade escolar acolhedora, receptiva, colaborativa e que incentive o êxito dos alunos. A dimensão política trata da escola para todos, organizando o apoio à diversidade; isso quer dizer que a inclusão precisa ser considerada em todos os planos da escola, bem como nas atividades, estratégias e outras formas de apoio com os princípios inclusivos.

Moura e Tamboril (2018) explicam que o conceito de diferença é central para a formulação e desenvolvimento de medidas de ações afirmativas, visto que por meio de políticas de focalização há o reconhecimento da exclusão socioeconômica causadora de discriminação e vitimização de determinados grupos sociais, bem como há a busca do enfrentamento desse processo por meio do aumento da participação desses grupos no processo político, no acesso a bens materiais e direitos universais e de valorização das diferentes culturas.

Omote et al., (2005) esclarecem que o acesso ou a inserção de um estudante com deficiência em qualquer sistema de ensino não significa que ele seja ou esteja incluído. Para os autores, muitas das decisões a serem tomadas para uma acolhida positiva e suporte ao estudante com deficiência, "visando o convívio produtivo a toda a sala, pode depender da correta compreensão da proposta da educação inclusiva e das atitudes sociais genuinamente favoráveis à inclusão por parte do professor [...]” (p. 388). Coadunando com essa lógica, Pacheco et al. (2007) afirmam que as relações sociais de estudantes e professores em sala de aula encorajam e aproximam ambos, no processo de inclusão.

\section{Metodologia}

Este artigo consiste em uma pesquisa de abordagem qualitativa, baseada no método de

RIAEE - Revista Ibero-Americana de Estudos em Educação, Araraquara, v. 15, n. esp. 2, p. 1553-1568, ago. 2020. e-ISSN: $1982-5587$. 
análise de conteúdo de fontes documentais que discutem normativas sobre a reserva de cotas na universidade, sendo lócus da pesquisa: Universidade Estadual Vale do Acaraú (UVA), Sobral, CE, e Universidade do Estado do Rio de Janeiro (UERJ), Rio de Janeiro, RJ.

Para análise dos dados, segue a proposta de Laurence Bardin (2009), em que trabalha a análise de conteúdo por meio da interpretação dos discursos dos sujeitos e de documentos, buscando sentido no que está explícito ou latente. Designa-se como um conjunto de técnicas de análise das comunicações, visando obter por procedimentos sistemáticos e objetivos de descrição do conteúdo das mensagens indicadores (quantitativos ou não) que permitam a inferência de conhecimentos relativos às condições de produção e/ou recepção (variáveis inferidas) destas mensagens (BARDIN, 2009).

Os dados coletados foram organizados da seguinte forma: levantamentos realizados in loco, e em instâncias responsáveis das universidades citadas anteriormente. Todo esse material foi organizado e codificado seguindo as etapas da análise de conteúdo de Bardin (2009). A nossa análise dos dados percorreu quatro etapas: (1) organização de todos os dados coletados; (2) identificação dos temas referente aos relatos; (3) criação das categorias de análise e (4) interpretação dos dados empíricos.

Os documentos são fontes das quais podem ser retiradas evidências que fundamentam as afirmações e as declarações do pesquisador. Representa uma forma de coletar dados, não apenas como uma fonte de informação contextualizada, mas que surge em um determinado contexto e fornece informações sobre este mesmo contexto (LÜDKE; ANDRÉ, 1986).

A etapa da coleta dos documentos refere-se a uma etapa importante da pesquisa documental, exigindo do pesquisador cuidados e procedimentos técnicos para chegar ao local para busca das fontes mais relevantes para a investigação; no caso desta pesquisa, as fontes que utilizamos encontramos em nossa pesquisa de campo nas universidades UERJ e UVA. Na primeira instituição foram selecionadas as Leis $n^{\circ} 3524$, de 28 de dezembro de 2000, $\mathrm{n}^{\circ} 3.708$, de $2001, \mathrm{n}^{\circ} 4.151$, de 2003, $\mathrm{n}^{\mathrm{0}} 5.346$, de 2008, dentre outras. Na segunda, foram levantados documentos que se referem à Lei ${ }^{\mathrm{o}}$ 12.077, de 1993, portaria ministerial, $\mathrm{n}^{\mathrm{o}}$ 821, de 1994; Lei $n^{\circ}$ 16.197, de 2017, Editais da Comissão Executiva do Processo Seletivo - CEPS: $n^{\circ}$ 08/2017, $n^{\mathrm{o}}$ 01/2018, no 09/2018, no 01/2019, nº 03/2019; e Política Nacional de Educação Especial na perspectiva da Educação Inclusiva, de 2008.

\section{Reserva de vagas para alunos com deficiência na UVA e na UERJ}

Compreende-se que o acesso às Instituições de Ensino Superior (IES) brasileiras pelas 
pessoas com deficiência é uma conquista recente nas políticas públicas educacionais do país, após anos e significativas dificuldades de enfrentamento por esse público em busca de escolarização, não só no ensino superior, como também na rede básica de ensino.

É importante observarmos que, a partir da Convenção sobre os Direitos das Pessoas com Deficiência (2007), pessoas com deficiência são aquelas que têm impedimentos de longo prazo de natureza física, mental, intelectual ou sensorial, os quais, em interação com diversas barreiras, podem obstruir sua participação plena e efetiva na sociedade em igualdades de condições com as demais pessoas, concepção ampliada com a Lei Brasileira de Inclusão, de 2015.

Com a lei $\mathrm{n}^{\mathrm{o}} 3524$, de 28 de dezembro de 2000, modificações nos critérios de acesso às universidades estaduais do Rio de Janeiro foram introduzidas: o mínimo de $50 \%$ das vagas no ensino superior público foi designado a estudantes oriundos de instituições públicas de educação básica dos Municípios e/ou do Estado. No ano seguinte, uma nova lei referente à reserva de vagas foi aprovada, a $\mathrm{n}^{\circ} 3.708 / 2001$, que destinou, então, o mínimo de $40 \%$ de vagas aos vestibulandos que se autodeclarassem negros ou pardos. Destacamos que nessa cota mínima estavam incluídos, inclusive, os negros e pardos beneficiados pela lei anterior.

Uma nova alteração às leis de 2000 e 2001 foi promulgada em 2003, a lei $n^{\circ}$ 4.151/2003, que substituiu as anteriores. Ainda sobre a reserva de vagas no sistema estadual de ensino superior público no Estado do Rio de Janeiro, citamos a lei $n^{\circ} 5.074 / 2007$, que destinou " $5 \%$ (cinco por cento) para pessoas com deficiência, nos termos da legislação em vigor, integrantes de minorias étnicas, filhos de policiais civis, militares, bombeiros militares e de inspetores de segurança e administração penitenciária, mortos em razão do serviço" (RIO DE JANEIRO, 2007).

Tendo em vista as modificações ocorridas em curto espaço de tempo, em 2008, a lei ordinária $n^{0} 5.346$ introduziu modificações significativas que permaneceram em vigor por dez anos. Ficou instituído que o ingresso de estudantes nas universidades estaduais pelo sistema de cotas seria assegurado, desde que fossem respeitadas a seleção e classificação final nos exames vestibulares. A reserva de vagas, portanto, passou a ter, inicialmente, o corte social. Os considerados carentes poderiam no ato da matrícula do vestibular optar por uma das categorias das cotas, que estavam definidas da seguinte forma: $20 \%$ para candidatos negros e indígenas, $20 \%$ destinadas a alunos da rede pública de ensino, e 5\% a pessoas com deficiência, segundo legislação vigente, a filhos de policiais civis e militares, bombeiros militares e inspetores de segurança e administração penitenciária, mortos ou incapacitados em razão do serviço.

RIAEE - Revista Ibero-Americana de Estudos em Educação, Araraquara, v. 15, n. esp. 2, p. 1553-1568, ago. 2020. e-ISSN: 1982-5587. 
A lei $n^{0} 5.346 / 2008$ também estabeleceu critério de avaliação para cada categoria a que se destinam as cotas, dos quais destacamos: 1) estudante carente no que se refere ao nível socioeconômico; 2) aluno oriundo da rede pública; 3 ) minorias éticas e pessoas portadoras de deficiência e filhos de policiais civis, militares, bombeiros militares e inspetores de segurança e administração penitenciária falecidos em razão do serviço; 4) o candidato deverá escolher no ato da inscrição por qual reserva de vaga irá concorrer; e 5) as universidades estaduais têm autonomia para adotar os atos e procedimentos necessários para a gestão do sistema, observados os princípios e regras estabelecidos na legislação estadual.

Com relação ao preenchimento das vagas reservadas aos cotistas, essas estarão distribuídas por todos os cursos e turnos oferecidos na universidade e, caso determinado grupo não preencha as vagas, respeitando-se a classificação, elas serão, obrigatoriamente, ocupadas por candidatos classificados dos demais grupos. Se, ainda assim, persistirem vagas não ocupadas, depois de esgotados todos os critérios estabelecidos para os candidatos que optaram pela reserva de vagas, essas vagas serão ocupadas pelos vestibulandos não optantes pelas cotas.

Também determinado pela lei $n^{\circ} 5.346 / 2008$, em 2017, foi instituída uma comissão para avaliação dos resultados dessa ação afirmativa e, a partir do relatório da referida avaliação, a reserva de vagas foi ratificada pela lei $\mathrm{n}^{\mathrm{o}} 8.121$, de 27 de setembro de 2018. Por mais 10 anos, os percentuais permaneceram os mesmos da $n^{\circ} 5.346 / 2008$, sendo que à categoria de negros e indígenas foram incluídos os alunos oriundos de comunidades quilombolas. As demais categorias permaneceram as mesmas, com os percentuais estabelecidos em 2008.

Também ficou mantida a autodeclaração nas inscrições para o vestibular e admissão para estudantes negros e indígenas, entretanto, é obrigação da universidade instituir Comissão Permanente de Assistência, a qual deve reconhecer ou não o direito à reserva de vagas estabelecido por Lei, apurando possíveis casos de frade ou falsidade ideológica.

Entendendo que é dever do Estado do Rio de Janeiro oferecer a inclusão social que se propõe a legislação desde 2008, na qualidade de carentes, aos estudantes ingressantes pelo sistema de cotas, para promover sua manutenção básica na Universidade, preparando seu ingresso no mercado de trabalho, são destinadas as seguintes ações complementares: I Pagamento de bolsa-auxílio durante o período do curso universitário; II - reserva proporcional de vagas em estágios na administração direta e indireta estadual; III - instituição de programas específicos de crédito pessoal para instalação de estabelecimentos profissionais ou empresariais de pequeno porte e núcleos de prestação de serviços (RIO DE JANEIRO, 2008). 
Além da chamada na UERJ de bolsa permanência, que hoje tem o valor de $\mathrm{R} \$ 500,00$ (quinhentos reais), os estudantes cotistas também podem acumular outra bolsa de igual valor ao ingressar em uma das modalidades de projetos oferecidas pela Universidade, iniciação à docência (ID), estágio interno complementar (EIC), monitoria (Mon) ou extensão (Ext); nesses casos, o estudante que ingressa na UERJ pelo sistema de reserva de vagas poderá receber até $\mathrm{R} \$ 1.000,00$ (mil reais), importância que o ajudará a manter-se na Universidade.

A Universidade Estadual Vale do Acaraú foi fundada por meio da Lei Municipal, $\mathrm{n}^{\mathrm{o}}$ 214, de 23 de outubro de 1968. Posteriormente, através da Lei $n^{\circ} 10.933$, de 10 de outubro de 1984, o poder executivo do estado do Ceará cria na forma de autarquia a Universidade Estadual Vale do Acaraú (UVA), que possui direito público e autonomia administrativa, financeira, patrimonial e didática no município de Sobral; e tem vinculação na Secretaria de Educação. Esse modelo de autarquia encampa a Faculdade de Ciências Contábeis, Enfermagem e Obstetrícia, Educação e Tecnologia, a Fundação Universidade Estadual Vale do Acaraú e a Faculdade de Filosofia Dom José, pertencentes à Diocese de Sobral.

Em seguida, transforma-se em Fundação Universidade Estadual Vale do Acaraú, que passa a ter vínculo à Secretaria da Ciência e Tecnologia, por meio da Lei ${ }^{0} 12.077$, cuja publicação no Diário Oficial do Estado (DOE), ocorreu em 22 de abril de 1993. Atualmente, o órgão de vínculo intitula-se Secretaria da Ciência e Tecnologia para Secretaria da Ciência, Tecnologia e Educação Superior (SECITECE). Em 1994 é reconhecida pelo Conselho de Educação do Ceará e sancionada pelo do Ministério da Educação e do Desporto, por meio da Portaria Ministerial nº 821, de 31 de maio de 1994.

Observa-se no caso do estado do Ceará que a Lei n. ${ }^{\circ}$ 16.197, de 17 de janeiro de 2017, traz sobre a instituição do Sistema de Cotas nas Instituições de Ensino Superior do Estado do Ceará; a lei estabeleceu o ano de 2018 para a efetivação da inclusão das cotas.

A Universidade Estadual Vale do Acaraú (UVA) deu início ao ingresso por cotas em 2018; assim, identificamos uma adesão tardia em relação à lei nacional para reserva de vagas. A Lei Estadual estabelece $\operatorname{cotas}^{4}$ : a) PPI - candidatos autodeclarados por pretos, pardos ou indígenas, b) SOCIAL - alunos de escola pública, c) PcD - pessoas com deficiências. A UVA implantou, inicialmente, apenas cotas para o primeiro caso. Somente em 2019 foi implementada a oferta de reserva de vagas em sua integralidade, contemplando as pessoas com deficiência. Também se verifica a existência de um pequeno grupo de docentes envolvidos nesta área, embora ainda não haja formalização diante da instituição (CEARÁ, 
2017).

Ressaltamos que a perspectiva por ações afirmativas para inclusão de pessoas com deficiência tem sua reserva de vagas garantida por meio da Lei de cotas e da Lei Brasileira de Inclusão, que se destinam a "assegurar e a promover, em condições de igualdade, o exercício dos direitos e das liberdades fundamentais por pessoa com deficiência, visando à sua inclusão social e cidadania" (BRASIL, 2015).

Mas é importante destacar que essas reservas devem ser minuciosamente observadas a cada processo seletivo. Principalmente quando observamos a necessidade de diagnóstico para o atendimento desses futuros estudantes no que se refere ao desafio no âmbito da docência universitária, devendo contribuir com ações pedagógicas inclusivas desde a elaboração de suas ementas, planejamento, prática docente, acessibilidade e responsabilidade pela docência no tocante à equidade de oportunidades. Assim, sintetizando com a afirmativa de Franco (2016, p. 607): “a prática pedagógica docente está profundamente relacionada aos aspectos multidimensionais da realidade local e específica, às subjetividades e à construção histórica dos sujeitos individuais e coletivos a prática docente é uma prática relacional.” Portanto, mediada por múltiplas determinações.

\section{Considerações finais}

Neste trabalho analisamos a articulação entre a reserva de vagas de duas instituições públicas de ensino superior e a docência universitária para práticas pedagógicas que visem combater a desigualdade racial, social e cultural, tendo como premissa a equidade de oportunidades. Dialogamos com alguns autores que se destacaram em nossa pesquisa no que se refere à temática da inclusão, assim como, com leis e decretos que justificam a implementação da política de cotas.

A pesquisa de campo foi realizada na UERJ e UVA, onde encontramos documentos que utilizamos como fontes nessa pesquisa, que foram analisados a partir da metodologia da análise de dados de Bardin (2009) e da pesquisa qualitativa, que permitiu uma análise aprofundada das questões propostas nesta pesquisa.

Neste artigo, buscamos evidências que criam condições para o aluno com deficiência avançar, considerando aspectos que possam implicar na docência universitária. Verificamos nas duas universidades estaduais a implementação de reservas de vagas, sendo que na UERJ a implementação foi total, além de uma política de permanência desses alunos, com a oferta de bolsa-auxílio de permanência, que atualmente tem o valor de quinhentos reais, podendo ser 
cumulativa com outra, que pode ser de iniciação à docência, estágio interno complementar, monitoria ou extensão; já na UVA, a implementação ainda é parcial, aceitando como cotistas apenas estudantes oriundos de escolas públicas, economicamente carentes e autodeclarados pretos, pardos ou indígenas, excluindo, assim, os estudantes que possuem alguma deficiência.

\section{REFERÊNCIAS}

AINSCOW, M. Tornar a educação inclusiva: como essa tarefa deve ser conceituada? In: FAVERO, O. (Org.). Tornar a educação inclusiva. Brasília: UNESCO, 2009.

BARDIN, L. Análise de conteúdo. Lisboa: Edições 70, 2009.

BOOTH, T.; AINSCOW, M. Index para a inclusão: desenvolvendo a aprendizagem e a participação na escola. Produzido pelo Laboratório de Pesquisa, Estudos e Apoio à Participação e à Diversidade em Educação - LaPEADE, FE-UFRJ. Trad. Mônica Pereira dos Santos. 3. ed. Substancialmente revisada e ampliada. Rio de Janeiro: Unesco/CSIE, 2000. Disponível em: http://www.lapeade.com.br/publicacoes/documentos/index2012final\%20FOTOS\%20BRASIL.pdf. Acesso em: 7 jun. 2019.

BRASIL. Ministério da Educação. Portaria n. 948/2007. Política Nacional de Educação Especial na Perspectiva da Educação Inclusiva. Brasília, 2008.

BRASIL. Lei de n. 9394, de 20 de dezembro de 1996. Lei de Diretrizes e Bases da Educação Nacional. Diário Oficial da União, Brasília, 23 dez. 1996. Disponível em: https://www2.camara.leg.br/legin/fed/lei/1996/lei-9394-20-dezembro-1996-362578publicacaooriginal-1-pl.html. Acesso em: 21 jan. 2010.

BRASIL. Lei n. 13.146, de 6 de jul. de 2015. Lei Brasileira de Inclusão da Pessoa com Deficiência. Diário Oficial da União, Brasília, 07 jul. 2015. Disponível em: http://www.planalto.gov.br/ccivil_03/_Ato2015-2018/2015/Lei/L13146.htm. Acesso em: 24 abr. 2017.

BUENO, J. G. S. Crianças com necessidades educativas especiais, política educacional e a formação de professores: generalistas ou especialistas? Revista Brasileira de Educação Especial, n. 5, p. 7- 23, set. 1999.

CEARÁ. Lei n. 16.197, 17de janeiro de 2017. Dispõe sobre a instituição do Sistema de Cotas nas Instituições de Ensino Superior do Estado do Ceará. Diário Oficial do Estado do Ceará, Fortaleza, Série 3, ano 9, n. 013, p.1, 18 jan. 2017.

CHAUÍ, M. Escritos sobre a universidade. São Paulo: UNESP, 2001.

FRANCO, M. A. S. Prática pedagógica e docência: um olhar a partir da epistemologia do conceito. Rev. Bras. Estudos Pedagógicos, v. 97, n. 247, p. 534-551, set./dez. 2016.

INSTITUTO NACIONAL DE ESTUDOS E PESQUISAS EDUCACIONAIS ANÍSIO TEIXEIRA. Censo Educacional. 2015. Disponível em: http://www.inep.gov.br/ 
basica/censo/default.asp. Acesso em: 16 jul. 2019.

INSTITUTO NACIONAL DE ESTUDOS E PESQUISAS EDUCACIONAIS ANÍSIO TEIXEIRA. Resumo técnico: Censo da Educação Superior 2015. 2. ed. Brasília: Instituto Nacional de Estudos e Pesquisas Educacionais Anísio Teixeira, 2018.

LIBÂNEO, J. C. Educação, Pedagogia e Didática: o campo investigativo da pedagogia e didática no Brasil. In: PIMENTA, S. G. (Org.). Didática e Formação de Professores: percursos e perspectivas no Brasil e Portugal. São Paulo. Cortez Editora, 2000.

LÜDKE, M.; ANDRÉ, M. E. D. A. Pesquisa em educação: abordagens qualitativas. São Paulo: EPU, 1986.

KARAGIANNIS, A.; STAINBACK, W.; STAINBACK, S. Fundamentos do Ensino Inclusivo. In: STAINBACK, S.; STAINBACK, W. Inclusão: um guia para educadores. Porto Alegre: Artmed, 1999. p. 35-47.

MANTOAN, M. T. E. O desafio das diferenças nas escolas. 5. ed. Petrópolis, RJ: Vozes, 2013.

MITTLER, P. Educação inclusiva: contextos sociais. Porto Alegre: Artmed, 2003.

MOURA, M. R. S; TAMBORIL, M. I. B. “Não é assim de graça!”: Lei de Cotas e o desafio da diferença. Psicol. Esc. Educ., Maringá, v. 22, n. 3, p. 593-601, dez. 2018. Disponível em: http://www.scielo.br/scielo.php?script=sci_arttext\&pid=S1413$85572018000300593 \& \operatorname{lng}=$ pt\&nrm=iso. Acesso em: 20 out. 2019.

OMOTE, S. et al. Mudança de atitudes sociais em relação à inclusão. Revista Paidéia, v. 32, n. 15, p. 387-398, 2005. Disponível em: http://sites.ffclrp.usp.br/paideia/artigos/32/07.htm. Acesso em: 03 jun. 2019.

PACHECO, J. et al. Caminhos para a inclusão: um guia para o aprimoramento da equipe escolar. Porto Alegre: Artmed, 2007.

PARRA, D. J. L.; INFANTE, G. R. Consideraciones en la Intervención Psicopedagógica en el alumnado universitario con discapacidad. Revista La Escuela Universitária de Magistério de Toledo, Toledo, Espanha, ano 31, n. 16, jan./dez. 2006.

PIMENTA, S. G.; ANASTASIOU, L. G. Docência no ensino superior. 2. ed. São Paulo: Cortez, 2005.

RODRIGUEZ, J. G.; GARZÓN, J. C. Cooperação escola-universidade e construção do currículo. In: GARCIA, R. L.; MOREIRA, A. F. B. (Org.) Currículo na contemporaneidade: incertezas e desafios. São Paulo: Cortez, 2012.

RIO DE JANEIRO. Lei n. 5074, de 17 de julho de 2007. Disponível em: https://govrj.jusbrasil.com.br/legislacao/87904/lei-5074-07. Acesso em: 03 ago. 2019.

RIO DE JANEIRO. Lei n. 5346, de 11 de dezembro de 2008. Lei sobre o novo sistema de cotas para ingresso nas universidades estaduais. Disponível em: https://gov- 
rj.jusbrasil.com.br/legislacao/87636/lei-5346-08. Acesso em: 03 ago. 2019.

SAWAIA, B. et al. As artimanhas da exclusão: análise psicossocial e ética da desigualdade social. 14. ed. Petrópolis: Vozes, 2014.

\section{Como referenciar este artigo}

SOARES, A. C.; OLIVEIRA, V. de. Reserva de vagas em universidades públicas estaduais: implicações para a docência universitária. Revista Ibero-Americana de Estudos em Educação, Araraquara, v. 15, n. esp. 2, p. 1553-1568, ago. 2020. e-ISSN: 1982-5587. DOI: https://doi.org/10.21723/riaee.v15iesp2.13828

Submetido em: 30/08/2019

Revisões requeridas: $30 / 11 / 2019$

Aprovado em: 02/02/2020

Publicado em: 01/08/2020 